\title{
Compestoto
}

\section{Mundaneum e Biblioteca Digital Mundial: relações possíveis?}

\author{
Zaira Regina Zafalon \\ Doutora; Universidade Federal de São Carlos, São Carlos, SP, Brasil; \\ zzafalon@gmail.com \\ Mariana Nóbrega de Sá \\ Graduada; Universidade Federal de São Carlos, São Carlos, SP, Brasil; \\ marianinhadesa@gmail.com
}

\begin{abstract}
Resumo: A contribuição de Paul Otlet para a Ciência da Informação, em específico nos estudos da Documentação, é notável. No contexto histórico entre as duas guerras mundiais, Otlet sonha com o Mundaneum, um centro de informação e produção de conhecimento em prol da paz mundial. Entre $2005 \mathrm{e}$ 2006, a Library of Congress, a UNESCO e outras cinco instituições, dentre as quais a Biblioteca Nacional do Brasil, propõem a criação da Biblioteca Digital Mundial. Por acreditar na importância que as instituições de patrimônio cultural e documental têm na curadoria de objetos informacionais para a formação histórica, educacional, política e social, buscaram-se respostas para a questão: seria a Biblioteca Digital Mundial a realização do Mundaneum? Com o objetivo geral de identificar aproximações entre o Mundaneum e a Biblioteca Digital Mundial, pela perspectiva histórica, a pesquisa percorre objetivos exploratórios. Com abordagem qualitativa e de natureza aplicada, faz-se uso de pesquisa bibliográfica e documental para a tessitura dos resultados. Arrisca-se a considerar que a Biblioteca Digital Mundial apresenta forte relação com o Mundaneum, embora essa identificação não tenha sido feita nas fontes documentais encontradas. A Biblioteca Digital Mundial se posta como a realização do sonho-utopia de Otlet, reúne e dissemina o conhecimento internacional, intercultural, com recursos informacionais dos mais diversos períodos, países, formatos e áreas do conhecimento. Apesar de terem sido identificados fortes vínculos entre elas, não foi notada a presença da proposta de Otlet para que o projeto da Biblioteca Digital Mundial tivesse visão integrada, estrutural, interdisciplinar, correspondente às funções da vida social, como propôs Otlet: biológica, reprodutiva, econômica, moral, intelectual, jurídica e política.
\end{abstract}

Palavras-chave: Mundaneum. Biblioteca Digital Mundial. Paul Otlet. UNESCO.

\section{Introdução}

A contribuição de Paul Otlet para a Ciência da Informação é notável, visto seu reconhecimento como um dos pioneiros a tratar da Documentação, junto a Henri 
de La Fontaine. De acordo com Rayward (2010, p. 3), Otlet foi um pensador à frente de seu tempo, principalmente quanto à propositura de recolhimento, seleção, organização, armazenamento e disseminação do conhecimento em atividades definidas na concepção do Palais Mondial ${ }^{1}$, chamado mais tarde de Mundaneum, instalado no Parc du Cinquantenaire, no centro de Bruxelas (1920).

Anteriormente à instalação do Palais Mondial, Otlet estabeleceu, em 1895, o Instituto Internacional de Bibliografia (IIB), com o Repertório Bibliográfico Universal (RBU) ou Bibliographia Universalis,

[...] projetado como um catálogo no qual deve estar registrada integralmente e ordenada toda a produção intelectual, em forma de inventário, e que a torna largamente acessível a todos e para todos os propósitos. Ele deve abarcar todas as obras, incluir os escritos de todos os tempos, produzidos em todos os países, em todas as formas, em quaisquer materiais. Dele farão parte livros, folhetos, folhas avulsas, revistas, jornais, publicações oficiais e obras didáticas. Estarão excluídas as partituras musicais, as estampas, a numismática, a epigrafia e os materiais de arquivos. (OTLET, 2018, p. 630)

Embora o projeto Mundaneum, de Otlet, não tenha se concretizado conforme o planejado, principalmente por conta da Segunda Guerra Mundial (1939-1945), grande parte de seus objetivos foram alcançados. RieussetLemarié (1997) afirma que o Mundaneum pode ser categorizado como uma rede de informação, compreendida como um corpo mundial onde se reuniriam registros da enciclopédia do conhecimento.

A Biblioteca Digital Mundial (BDM), por sua vez, define-se como um ambiente digital online que "[...] disponibiliza na Internet, gratuitamente e em formato multilíngue, importantes fontes provenientes de países e culturas de todo o mundo." (BIBLIOTECA DIGITAL MUNDIAL, [2009?]). Com proposta de criação feita por James H. Billington, bibliotecário da Library of Congress, à UNESCO, em 2005, a BDM é discutida em Reunião de Peritos, co-patrocinada pela UNESCO e pela Library of Congress, em 2006, com a participação de várias partes interessadas. A proposta foi discutida e as dificuldades identificadas, tais como, a quantidade de conteúdo cultural digitalizado disponível, até por conta da baixa capacidade de digitalização por parte de vários países; as precárias funções de pesquisa e de exibição dos objetos nos 
web sites institucionais; a falta de desenvolvimento de acesso multilíngue, dentre outros. Em seguida, formaram-se grupos de trabalho para alinhavar o projeto e desenvolver e contribuir em conteúdo para um protótipo. Além das instituições envolvidas na proposta do evento, comprometeram-se para a realização destas atividades a Bibliotheca de Alexandria, a Biblioteca Nacional do Brasil, Biblioteca e os Arquivos Nacionais do Egito, a Biblioteca Nacional da Rússia e a Biblioteca Estadual da Rússia.

Com recursos da UNESCO e da International Federation of Library Association and Institutions (IFLA), o protótipo da BDM foi apresentado em 2007, na Conferência Geral da UNESCO, fato que incentivou várias bibliotecas do mundo a desenvolverem uma versão pública e de livre acesso da BDM, culminando em seu lançamento, em 2009, em nível internacional, com conteúdo sobre cada estado-membro da UNESCO.

Pelo fato de as autoras deste estudo acreditarem no papel relevante desempenhado por Otlet no desenvolvimento de estudos e pesquisas que subsidiaram a organização de bibliotecas e de centros de documentação, por considerarem que a paz mundial por meio do compartilhamento de documentos seria uma conquista extraordinária e, diante da importância que as bibliotecas e os museus tem na curadoria de objetos informacionais para a formação histórica, educacional, política e social, buscaram-se respostas para a questão: seria a Biblioteca Digital Mundial a realização do Mundaneum?

Com o objetivo geral de identificar aproximações entre o Mundaneum e a Biblioteca Digital Mundial, a pesquisa apresenta abordagem qualitativa e natureza aplicada. Em busca dos objetivos específicos de contextualizar tanto o Mundaneum quanto a Biblioteca Digital Mundial, pela perspectiva histórica, a pesquisa percorre objetivos exploratórios e faz uso de pesquisa bibliográfica e documental para a tessitura dos resultados.

As autoras vislumbram que, por conta de o foco desta pesquisa considerar a BDM, seja possível, como contribuição social, valorizar o patrimônio cultural nacional, bem como o de coleções de outros países e de outras instituições, como bibliotecas, galerias de arte, arquivos e museus, e que sejam incrementadas, em âmbito nacional e internacional, ações de preservação da memória cultural. 
No campo acadêmico, propõe-se o questionamento crítico de ações e propostas que marcaram e, por que não dizer, delinearam a trajetória teóricoprática na Biblioteconomia, bem como de estudiosos que são referência, neste caso, Paul Otlet.

\section{Referencial teórico}

Tendo em vista a perspectiva do historicismo, considerou-se, no desenvolvimento do referencial teórico, o levantamento bibliográfico em bases de dados, periódicos, livros, teses, anais de eventos e sites disponíveis na internet, a fim de identificar trabalhos que permitissem resgatar aspectos que relacionassem Otlet e o Mundaneum, e estudos sobre a Biblioteca Digital Mundial. As bases de dados selecionadas para a pesquisa foram: Biblioteca Digital Brasileira de Teses e Dissertações (BDTD), Bases de Dados Referencial de Artigos de Periódicos (BRAPCI), E-prints in Library and Information Science (E-LIS), Scientific Electronic Library Online (SciELO), Wiley Online Library, e Web of Science (WoS). ${ }^{2}$

Realizada a pesquisa nas bases de dados, com buscas nos campos autor, título e assunto, foi possível obter 112 registros que relacionavam ${ }^{3}$ Paul Otlet e Mundaneum. Não houve, porém, nenhum retorno sobre a BDM, daí a adoção de pesquisa documental no site do próprio ambiente. Tendo sido identificadas as duplicatas, as mesmas foram descartadas, o que totalizou a análise de 98 documentos ${ }^{4}$ : 66 artigos de periódicos, 14 teses, cinco livros, cinco trabalhos de eventos, quatro dissertações, três capítulos de livros e um trabalho de conclusão de curso de especialização.

Os artigos foram publicados nos periódicos ${ }^{5}$ Journal of the American Society for Information Science (12), Journal of the American Society for Information Science and Technology (quatro), Annual Review of Information Science and Technology (quatro), Ciência da Informação (quatro), Revista Interamericana de Bibliotecología (quatro), Información, Cultura y Sociedad (três). Dentre os periódicos científicos nacionais destacam-se: Brazilian Journal of Information Science, Ciência da Informação, DataGramaZero, Informação \& Informação, Ponto de Acesso e Revista ACB: Biblioteconomia em Santa 
Catarina.

Dentre os autores, foram identificados 102, dentre os quais 87 com publicação única. Os autores ${ }^{6}$ com maior número de publicação são: Michael Buckland (sete), Rodrigo Rabello (cinco), W. Boyd Rayward (quatro), Ronald E. Day (três), e, com três publicações cada, Juan Manuel Zurita Sánchez e Susana Romanos de Tiratel. O autor brasileiro de destaque, Rodrigo Rabello, é docente na Universidade de Brasília, e contribuiu com dois artigos de periódicos, dois capítulos de livro e um trabalho de evento.

Dentre teses, destacam-se a Universidade Federal do Rio de Janeiro (sete), seguida de Universidade de Brasília e Pontifícia Universidade Católica de Campinas, ambas com duas ocorrências, e, com um trabalho cada, Universidad Nacional Autónoma do México, Universidade de Coimbra e Universidade de São Paulo. As dissertações foram apresentadas em cursos da Universidade Federal de São Carlos (duas), Universidade de São Paulo e Universidade Federal do Rio de Janeiro.

A primeira publicação encontrada nas bases de dados referenciadas nesta pesquisa é de 1954, um artigo de periódico. A primeira tese, de Lena Vânia Ribeiro Pinheiro, foi defendida em 1997, na Universidade Federal do Rio de Janeiro.

Pode existir um número maior de documentos voltados às discussões sobre Paul Otlet e seu projeto Mundaneum nas bases de dados selecionadas e que não foram identificadas nesta pesquisa por não adotarem os termos adotados como indexador nos campos determinados. Apesar disso, considerou-se que os critérios utilizados se mostraram válidos para o propósito desta pesquisa, visto que, assim, foi possível desenvolver o conteúdo do referencial teórico.

\subsection{Paul Otlet e o sonho-utopia do Mundaneum}

Paul Marie Ghislain Otlet (Bruxelas, Bélgica, 23 de agosto de 1868 - Bruxelas, Bélgica, 10 de dezembro de 1944) formou-se em advocacia e tinha amplo conhecimento em várias outras áreas, como sociologia, bibliografia, arquitetura e urbanismo.

O documentário L’homme qui voulait classer le monde (2002), com 
direção de Françoise Levie, retrata com muito cuidado a vida de Otlet e destaca, dentre os seus feitos: a criação do Instituto Internacional de Bibliografia, a organização do Repertório Bibliográfico Universal; a definição do Manuel du Répertoire Bibliografique Universel, publicado oficialmente em 1905, que, a partir da segunda edição, publicada em 1927, passou a ser designado como Classificação Decimal Universal; a definição de um método que desse conta da complexidade e do alcance internacional que a proposta do RBU requeria, daí a adoção de padrões, tanto em relação às fichas bibliográficas - nomeadas como bibliographic cards por Rayward (2010) - quanto ao seu arranjo em gabinetes; a criação do microfilme; a proposta do Palais Mondial; a concepção da Bibliothèque irradiée, que permitiria o acesso remoto aos livros por meio de um aparato que unia tela de televisão a um telefone; e, o que não pode deixar de ser mencionado, o sonho de paz universal.

Com a grandeza que o RBU alcançou, com sete milhões ${ }^{7}$ de fichas, Otlet passa a ter a convicção de que a divulgação do conhecimento ali registrado influenciaria a vida das pessoas despertando-as para um pensar mais crítico e reflexivo, o que viria a colaborar para a paz mundial. Como Rayward (2010, p. 3) já havia indicado, Paul Otlet era um pensador que capitaneava ideias, o que se percebe pela sua visão de museu, que concebeu como um local de gente curiosa, sendo que "[...] para muitos de seus contemporâneos era um gabinete de curiosidades". O próprio Mundaneum foi pensando a partir desta concepção de museu! Pensando dessa forma mais ampla, Otlet abre, no Parc $d u$ Cinquantenaire, no centro de Bruxelas, o Palais Mondial, posteriormente chamado de Mundaneum, com uma proposta muito mais ampla que um museu da época, embora com características semelhantes.

Estava, então, caracterizado o Mundaneum como um projeto que reuniria e disseminaria o conhecimento universal em um só lugar físico, com acesso universal, por meio de uma rede global. Projetado com visão integrada, estrutural, ou circular, do local físico, o Mundaneum previa funções da vida social presentes: biológica, reprodutiva, econômica, moral, intelectual, jurídica e política. Além dessas funções, também havia o cuidado na identificação de organismos: local, regional, nacional e internacional. No centro de tudo, mediado por uma rede de comunicação, cooperação e intercâmbio, seria 
formado o centro mundial: o Mundaneum (RABELLO, 2012 p. 110).

Otlet e Otto Neurath, de acordo com Wright (2014, p. 194), compactuavam da ideia de uma rede de museus, como se fossem elos do Mundaneum, que seria composta por diversos materiais e coleções de vários países. Os museus, para ambos, destinavam-se a promover mudanças sociais e o futuro deles dependeria da participação dos seus visitantes para moldar suas exposições.

Quanto ao projeto arquitetônico do Mundaneum, Otlet teve a colaboração do arquiteto Le Corbusier, que possuía uma linguagem notavelmente similar à de Otlet, usando termos como plano, padronização e síntese para caracterizar suas respectivas visões de um futuro idealizado. A cidade mundial seria projetada para abrigar um novo governo de um mundo com um repositório de informações em rede. (WRIGHT, 2014).

Vossoughian (2003, p. 85) afirma que o projeto do Palais Mondial estabeleceria padrões bibliográficos e documentais para a manutenção e preservação de culturas ao redor do mundo e que atuaria como um local de encontro para discutir e trocar ideias políticas, sociais e culturais. Para Rayward (2010, p. 35), o Palais Mondial tinha como ponto central levar a paz em forma de conhecimento: "[...] que ele se tornasse uma prática, um instrumento que poderia ajudar a alcançar a harmonia universal promovendo o progresso."

Por meio das ações do IIB, Otlet tem contato com várias associações e, em 1910, propõe, organiza e convoca o Congresso Mundial de Associações Internacionais. Para Otlet, as associações internacionais eram fundamentais no desenvolvimento da Cidade Mundial, dando o caráter internacional ao seu projeto.

Ainda com o intuito de contribuir para a paz, Otlet, no começo da primeira guerra mundial, publica, em 1914, o livro intitulado La Fin de la guerre: traité de paix générale basé sur une charte mondiale déclarant les droits de l'humanité et organisant la confédération des états, no qual apresenta a Liga das Nações ${ }^{8}$, cuja finalidade era “[...] manter a paz, garantir os direitos internacionais e governar para o interesse comum de toda humanidade." (L'HOMME..., 2002). Em 1916, em Les problèmes internationaux et la guerre, Otlet conceitua a Liga das Nações (L’HOMME..., 2002). 
Em 1917, com a morte de seu filho Jean ${ }^{9}$ na guerra, Otlet se vê abalado e promete vingar-se. A vingança viria por meio do trabalho em prol do mundo livre de guerras. Com o retorno do Rei Alberto I à Bélgica, em 1918, Otlet recebe o apoio necessário para a realização do seu projeto: a ala da União das Associações Internacionais no Parc du Cinquantenaire. Em 1920, então, é inaugurado o Palais Mondial, dentro do museu internacional no Parc $d u$ Cinquantenaire. Otlet vê seu sonho ser concretizado.

O Mundaneum é, para Otlet (2018, p. 650), um “[...] centro científico, documentário, educativo e social, desenvolve-se em três direções: como ideia, como instituição e como corpo físico de coleções e serviços."10

[...] é uma ideia de universalismo. É uma instituição em que são reunidos "o museu para ver, o cinema para assistir, a biblioteca, enciclopédias e arquivos para ler, o catálogo para consultar, a palestra, o rádio e os discos para ouvir, e a conferência para debater." [...] É um método que implica, entre outras coisas, "pesquisa e previsão, unificação e padronização, ordenação e classificação, cooperação, planejamento e regulação, por fim, expressão, apresentação e reprodução". [...] É um edifício físico a ser realizado arquitetonicamente. É, afinal, uma rede. (OTLET, 1935, p. 448-452 apud RAYWARD, 2018, p. xv, destaque do autor). ${ }^{11} 12$

Otlet $(2018$, p. 651) também estabelece princípios para a realização do Mundaneum: "[...] totalidade, simultaneidade, gratuidade, voluntariedade, universalidade e mundialidade". Tais princípios parecem estar evidentes, embora não tenham sido explicitados pelo próprio Otlet, no detalhamento da abrangência de La Cite Mondiale (cf. Figura 1): 1) a representação total das forças da Terra, 2) o símbolo da Humanidade, 3) o observatório da vida mundial, 4) o conservatório de protótipos, 5) o centro geral de cooperação, e 6) bolsas de estudos para novas ideias e concessão para projetos de toda natureza. Além dessas representações, La Cite Mondiale, envolveria [I] a documentação mundial, [II] a universidade mundial, [III] o museu mundial, [IV] a união mundial das associações internacionais, [V] a exposição universal permanente, [VI] a cidade modelo, [VII] o centro da vida internacional, e [VIII] o centro de turismo mundial. 


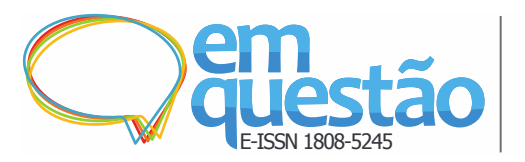

Mundaneum e Biblioteca Digital Mundial: relações

possíveis?

Zaira Regina Zafalon e Mariana Nóbrega de Sá

Figura 1 - Abrangência da Cidade Mundial

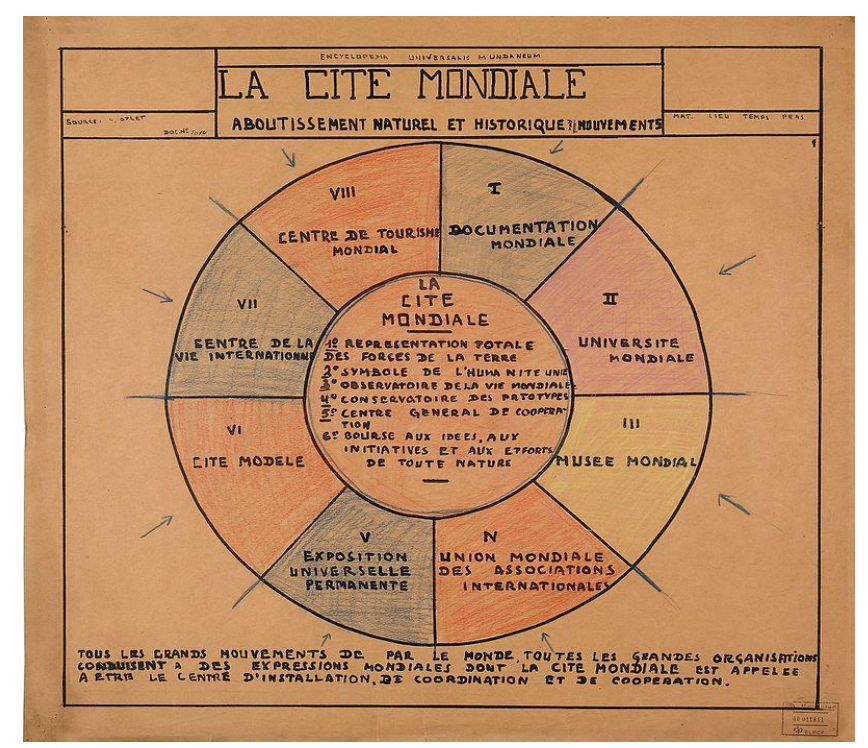

Fonte: Wikimedia Commons (2016).

Quanto à missão do Mundaneum, Otlet (2018, p. 654) a concebe a partir de três objetivos:

$1^{\circ}$ Ser um instrumento prático para a cooperação internacional, em todos os domínios, à semelhança do que, em cada país, faz a capital ao facilitar a cooperação em escala nacional. $2^{\circ}$ Oferecer a oportunidade, com a união de todas as forças, para construir uma cidade-modelo, pois ela seria realizada com base em um plano, de uma vez, e libertada assim das contingências das cidades antigas que são difíceis de transformar. $3^{\circ}$ Enfim, constituir uma representação e um símbolo permanente da unidade humana.

Apesar de os dados estatísticos ${ }^{13}$ quanto ao trabalho desenvolvido serem otimistas, o governo da Bélgica, em 1934, decide encerrar as atividades do Palais Mondial e o trabalho do IIB. Em 1941, durante a Segunda Guerra Mundial, os alemães ocuparam o Parc $d u$ Cinquantenaire e as coleções passaram a ficar no Parc Léopold ${ }^{14}$, em um espaço reduzido. Apesar de ter sido retomada a posse do Parc du Cinquantenaire, prosseguir com o projeto tornouse mais difícil, visto que a coleção permanecia no Parc Léopold. Rayward (2010, p. 12) afirma que, com a morte de Otlet, em 1944, Georges Lorphèvre e André Colet trabalharam para dar continuidade ao projeto Mundaneum e organizaram vários programas educacionais.

Rayward (2018, p. xxiii) cita a criação de um novo Mundaneum, em Mons (Bélgica), entre 1995-1996, resultado do esforço iniciado por André Cannone, dez anos antes, ainda em Liège. O novo Mundaneum, um misto de 
arquivo e museu, é voltado às obras de Otlet e de La Fontaine. O acervo conta com o que foi possível resgatar do Mundaneum.

$\mathrm{Na}$ página do Mundaneum na internet, que é extremamente informativa, é apresentada uma descrição da amplitude da instituição, uma introdução sobre Otlet e La Fontaine, além da história do Mundaneum e de suas várias mudanças, de uma espécie de armazém inadequado para outro, junto com as perdas de documentos que tais mudanças causavam. (RAYWARD, 2018, p. xxiii).

O sonho foi sonhado, realizado e continua...

\subsection{Biblioteca Digital Mundial: propostas e ações}

O cenário vivenciado na atualidade é bem diferente daquele do tempo em que Otlet viveu. Gantz e Reinsel (2012, tradução nossa) afirmam que “[...] o universo digital vive cada vez mais em uma nuvem de computação, com grandes quantidades de dados de hardware ligados a milhares de milhões de dispositivos distribuídos, todos governados e definidos por softwares cada vez mais inteligentes".

A demanda de usuários e as inovações tecnológicas trouxeram novas reivindicações às unidades de informação, tal como Otlet apresentou um século antes, de modo que foram buscadas outras formas de suprir o atendimento às necessidades de informação destes usuários, mas também, de outros, as máquinas, visto que a automação de inúmeros processos, por meio de intercâmbio de dados tem protagonizado a oferta de novos produtos pelas mais variadas instituições.

O ambiente digital tem se firmado, portanto, em um espaço sem precedentes para o registro, o tratamento e a recuperação de documentos textuais, sonoros e imagéticos e, ao favorecer a armazenagem, a interoperabilidade entre sistemas e a compatibilidade entre formatos, passou, também, a requerer para si novas responsabilidades de busca e recuperação.

Nesse cenário de inovações e tecnologias, em reunião da Comissão Nacional (USA) para a UNESCO, realizada em 6 de junho 2005, na Georgetown University, James H. Billington, diretor da Library of Congress, apresentou, na plenária de abertura, a proposta conceitual da Biblioteca Digital 
Mundial. (LIBRARY OF CONGRESS, [2000?]).

James H. Billington (1929-2018) foi o décimo terceiro diretor da Library of Congress, tendo ocupado essa posição no período de 1987 a 2015. Ao longo dos 28 anos à frente da instituição, teve feitos memoráveis, com destaque para American Memory, em 1990, Congress.gov, em 2012, depois de Thomas.gov, em 1994; Educational portal for K-12 teachers and students, em 1996; "eCo", em 2008; World Digital Library, em 2009; Resource Description and Access (RDA), em 2010; BIBFRAME, em 2011; National Jukebox, em 2011; BARD, em 2013; e a presença da Library of Congress em redes sociais desde 2007, entre elas 14 blogs, Flickr, Facebook, iTunesU, Pinterest, RSS, Twitter, YouTube e Instagram. (LIBRARY OF CONGRESS, [2018?]).

Foi também com a participação de Billington que a Library of Congress estabeleceu vários programas: The National Book Festival, Literacy Awards, The John W. Kluge Center, The Kluge Prize for Achievement in the Study of Humanity, The Audio-Visual Conservation Center, National Film Preservation Board, Veterans History Project, National Recording Preservation Board, The Gershwin Prize for Popular Song, The Library of Congress Prize for American Fiction, Young Readers Center, Junior Fellows, Gateway to Knowledge (LIBRARY OF CONGRESS, [2018?]).

O discurso feito naquela ocasião por Billington (2005, tradução nossa) demonstrou preocupação com a educação: “[...] a maioria das partes do mundo com que temos que nos preocupar são sociedades esmagadoramente jovens, com instalações educacionais esmagadoramente inadequadas, e a educação, em certo sentido, afeta tudo." Apesar de destacar o ponto de vista sobre a educação, Billington (2005) afirmou que apresentar uma nova proposta, com nova tecnologia, não traria paz, harmonia ou justiça por si só e, tampouco, teria condições de transformar a perversidade humana.

Van Oudenaren ([2012?]) afirma que a proposição de Billington foi feita em uma época em que, após uma ausência de quase 20 anos, os Estados Unidos estavam em processo de se unir à UNESCO. Talvez, e isso é uma inferência, esteja aí a motivação para a apresentação de sua proposta: Otlet fez esse mesmo movimento em prol de união das nações à época. Nas palavras de Billington (2005, tradução nossa), “[...] talvez seja a hora de a delegação de nosso país 
considerar a possibilidade de apresentar ao organismo mundial uma proposta de construção cooperativa de uma biblioteca digital mundial." O proponente também argumentou que isso poderia dar novos ares à UNESCO, além de favorecer benesses a todos. "Isso manteria a promessa de aproximar as pessoas precisamente celebrando a profundidade e a singularidade de diferentes culturas em um único empreendimento global compartilhado.” (BILLINGTON, 2005, tradução nossa).

Billington (2005) apresentou, como argumento para a Biblioteca Digital Mundial, o fato de estarem em curso dois projetos de digitalização bilíngue para mesclar documentos primários, da coleção da Library of Congress, com os das bibliotecas de outros seis países, e destacou, como dois experimentos mais avançados, o projeto com a Rússia e com o Brasil, selecionados como piloto por conta da multiculturalidade e do tamanho continental de ambos. Billington (2005) afirmou que os sites destes projetos não foram feitos somente para os Estados Unidos, visto que estavam sendo usados em Boston, Moscow, Amsterdam e São Paulo, bem como Chicago, Houston, e Los Angeles.

Apesar de Billington (2005, tradução nossa) ter exposto essa proposição a ser levada à UNESCO, ele já ponderava a realização do projeto pela instituição:

\footnotetext{
Esses projetos globais poderiam começar, mas não precisam terminar nos esforços multinacionais através da UNESCO, ou catalisados pela UNESCO de alguma forma, para começar a digitalizar projetos de memória on-line para três grandes regiões culturais, cada qual além da Europa e da cultura europeia e da cultura do Atlântico Norte ou Sul, para esse assunto. Cada um deles envolve mais de um bilhão de pessoas do mundo, em cada caso com uma população forte, crescente e mais jovem.
}

Billington (2005) defendia que os projetos culturais deveriam ser criados com e pelas pessoas das respectivas regiões, o que não impediria o desenvolvimento paralelo ou rival de projetos, quer fossem semelhantes ou diferentes, em qualquer outra parte do mundo. O que faria com que esses projetos fossem consagrados como internacionais seria a Internet, visto que é, por definição internacional. Os planos também consideraram o apelo humano por meio de documentos primários, por conta do 
[...] potencial para aumentar a compreensão transcultural por meio do diálogo que os acadêmicos e curadores colocariam juntos em pacotes de memória, e através do impacto que eles podem ter no pensamento de jovens globalmente curiosos e extremamente orientados para multimídia em todo o mundo que cada vez mais têm sua própria cultura de pares e suas próprias expectativas. (BILLINGTON, 2005, tradução nossa).

Quanto à estrutura, Billington (2005) alegou que grande quantidade de material online já estava disponível, ou programado para, em repositórios dos Estados Unidos e no exterior. Isso implicaria envolver todas as partes interessadas, privadas e públicas, locais e federais, e até com participação estrangeira.

Com o intuito de que a BDM fosse entendida como uma enciclopédia online confiável de objetos culturais bidimensionais mais importantes e interessantes, Billington (2005) afirmou que este seria um projeto unitário, com diversos participantes, nos mesmos moldes do que a UNESCO criou para os monumentos históricos tridimensionais, porém, com uma vantagem: apesar de este atingir muitas pessoas, é necessário que elas se desloquem até onde os monumentos estão; o projeto da BDM, por envolver objetos bidimensionais em meio digital, alcançaria um público muito maior, sem a necessidade de deslocamento, visto que o acervo poderia ser conhecido a partir de qualquer lugar, onde quer que as pessoas estiverem!

Apesar de a proposta ser interessante e envolver comunidades de partes interessadas, duas questões teriam que ser enfrentadas, segundo Billington (2005): proteção de direitos autorais versus maximização da acessibilidade na Internet; e, metadados a serem operados transculturalmente e multimidiaticamente.

Além de Billington (2005) considerar legítimo o interesse nacional de que as tecnologias fossem usadas internacionalmente pelo setor privado, de modo a promover empreendimentos econômicos lucrativos, e pelo setor público, para promover instituições democráticas, também seria necessária uma política cultural estrangeira mais pró-ativa e inclusiva.

Com a biblioteca digital mundial, a rica reserva da cultura mundial que as instituições, bibliotecas e museus americanos preservaram poderia ser devolvida gratuitamente ao mundo e, de uma forma nova, muito mais universalmente acessível do que qualquer outra 
forma anterior. [...] Além disso, porém, a própria América é uma civilização mundial que agora inclui de maneira singular em seus cidadãos um número significativo de pessoas de todas as partes do mundo. Uma parceria público-privada americana patrocinando tal projeto para a UNESCO dramatizaria o fato de estarmos ajudando outras culturas a recuperar elementos distintos de suas próprias culturas por meio de um empreendimento compartilhado que também pode tornar psicologicamente mais fácil para eles descobrirem que o conhecimento e a experiência da nossa própria e de outras culturas livres, democráticas, participativas e responsáveis podem ser mais benéficas para o seu desenvolvimento e para o seu próprio bem-estar do que, de outra forma, estariam dispostas a admitir até para si mesmas. (BILLINGTON, 2005, tradução nossa).

Van Oudenaren ([2012?]) esclarece que, apesar de ter sido constituída uma equipe para que a visão de Billington se tornasse realidade, decisões sobre a arquitetura técnica, seleção de conteúdo, público-alvo e modos de participação ainda precisariam ser tomadas.

O projeto teve início com o recebimento de apoio financeiro da Google apesar de a UNESCO ter dúvidas sobre como seria sua participação e bibliotecários e acadêmicos americanos também verem problemas nisso -, e a IFLA manifestou interesse em colaborar; na Europa, diante da iniciativa de uma biblioteca digital europeia, houve dúvida sobre como conciliar as duas propostas; e, claro, como se nota em vários discursos, havia suspeitas sobre o imperialismo cultural americano. (VAN OUDENAREN, [2012?]).

Tendo decorrido sete anos do lançamento da proposta por Billington, Van Oudenaren ([2012?]) apresentou as decisões e escolhas que precisaram ser feitas para a efetivação da Biblioteca Digital Mundial. ${ }^{15}$ Os esforços da equipe começaram pela busca de respostas às perguntas:

\footnotetext{
- como deve ser uma Biblioteca Digital Mundial para ser digna deste nome?

- que capacidade, características e conteúdos devem ser oferecidos para que as pessoas realmente achem útil?

- que valor agregado ela deve oferecer para atrair usuários que já tem acesso ao Google?

- como deve diferir ou complementar a matriz de projetos de bibliotecas digitais nacionais e internacionais às quais as pessoas já tem acesso? (VAN OUDENAREN, [2012?], tradução nossa).
}

O ânimo para a realização do projeto veio por conta de três enfoques principais para a BDM: o multilinguismo, a universalidade, e o alto nível de valor agregado voltado para usuários reais. Van Oudenaren ([2012?]) explica que, quanto ao multilinguismo, tanto o conteúdo quanto o acesso deveriam ser 
preocupação fundamental: havia línguas ameaçadas e a própria UNESCO tinha interesse particular nelas; quanto ao acesso, havia um desafio maior, e que não poderia ser evitado: como dar acesso multilíngue?; em quais idiomas? Daí a decisão pela interface nas línguas oficiais das Nações Unidas: árabe, chinês, espanhol, francês, inglês e russo. Por conta da participação da Biblioteca Nacional do Brasil, co-fundadora do projeto, o português também foi adicionado. Com o objetivo de fornecer uma experiência centrada no usuário, todas as informações de navegação e os metadados foram adicionados nestes idiomas, com tradutores profissionais e especialistas no assunto (mesmo recorrendo à tradução automática), por conta de documentos raros e históricos que, por sua natureza, estão enraizados nas tradições culturais e contextos linguísticos nacionais.

Quanto ao princípio da universalidade, Van Oudenaren ([2012?]) aborda a participação e o conteúdo: a BDM estaria aberta para bibliotecas, arquivos e museus que estivessem prontos para colaborar com o fornecimento de conteúdo relevante para o resgate da história coletiva da humanidade. Essa grande abertura quanto à participação na BDM levantou questões referentes ao armazenamento, ao que foi proposto a replicação das experiências já vividas com a Rússia e o Brasil em acordos anteriores da Library of Congress. Faltariam, porém, recursos humanos e financeiros para que os treinamentos fossem promovidos!

O terceiro aspecto referia-se à funcionalidade e ao valor agregado ao usuário, o que estava intrinsecamente ligado ao planejamento, prototipagem e desenvolvimento do projeto. Quanto ao valor agregado, era fundamental a preocupação com a seleção do conteúdo, daí a opção por “[...]construir um corpo representativo de conteúdo relacionado à história e cultura de todos os países, com cultura definida em amplo sentido antropológico, com um foco intenso em coleções especiais e documentos raros e únicos." (VAN OUDENAREN, [2012?], tradução nossa). A prioridade, então, foi dada aos documentos listados em Memória do Mundo $^{16}$, da UNESCO. Outro fator relacionado ao valor agregado ao usuário era quanto à descoberta e exibição de conteúdo, daí a relação fundamental com os metadados ${ }^{17}$ e, por extensão, aos recursos de pesquisa e navegação. A intenção da equipe gestora da BDM, 
todavia, era ainda maior: além da descoberta e da exibição de conteúdo, este também seria explicado e interpretado; daí a decisão de que os registros seriam aprimorados de modo a ter a exibição da descrição em nível do item. Com conteúdo e metadados em sete idiomas, essa abordagem teria condições de garantir a experiência uniforme aos usuários, independente do local de acesso e da instituição que fornecesse o conteúdo. "Essa escolha de arquitetura, por sua vez, possibilitou alguns outros recursos, por exemplo: conversão de metadados e descrições de texto para fala, e opções padronizados de download de conteúdo." (VAN OUDENAREN, [2012?], tradução nossa).

O protótipo da BDM foi apresentado na Conferência Geral da UNESCO, realizada em Paris, em outubro de 2007, com conteúdo fornecido por seis instituições parceiras: a Biblioteca Nacional do Brasil, a Bibliotheca Alexandrina de Alexandria (Egito), a Biblioteca Nacional e Arquivo do Egito, a Biblioteca Nacional da Rússia, a Biblioteca Estadual Russa e a Biblioteca do Congresso. Van Oudenaren ([2012?]) também relatou que o lançamento oficial da BDM ocorreu na sede oficial da Unesco, em Paris, em 21 de abril de 2009, com contribuição de 18 países para o conteúdo, incluindo as bibliotecas nacionais de China, França, Israel, Japão, Rússia, Sérvia e Suécia, e bibliotecas universitárias de vários países.

Diante da preocupação dos membros fundadores com a governança, a BDM foi reestruturada em 2010 “[...] para se tornar uma instituição multilateral flexível com um conjunto uniforme de regras, uma estrutura de governança permanente e uma simples declaração de direitos e responsabilidades, incluindo direitos de propriedade intelectual.” (VAN OUDENAREN, [2012?], tradução nossa).

Também foi a partir de 2010 que a gestão da BDM passou a ser de um Conselho Consultivo, cabendo, à Library of Congress, a gerência de projeto institucional.

Van Oudenaren ([2012?]) destacou que o compromisso com o multilinguismo mostrou-se válido (o conteúdo estava em 86 idiomas) e que o acesso multilíngue havia sido um sucesso (o website em espanhol contabilizou $33,1 \%$ dos acessos, em 2009, e 58,4\%, em 2011). Apesar de o acesso em espanhol ter aumentado, e, em português, ter dobrado em 2011 (14,4\%) em 
relação a 2009 (7,7\%), a construção de altos níveis de uso da BDM na América Latina e nos países da Península Ibérica foram destacados como prioridade.

O compromisso com a universalidade continuou válido. Van Oudenaren ([2012?]) apresentou dados de a BDM ter 159 parceiros de 75 países. Apesar de não ter participação universal no momento da elaboração do relatório, já contavam com representantes de todos os continentes.

A valorização de conteúdo universal continuou presente e continuava como prioridade na seleção. "Os níveis de uso e de satisfação do usuário sugerem que as decisões relacionadas à funcionalidade e ao valor agregado ao usuário foram válidos. Em seu primeiro dia, a BDM recebeu mais de $600 \mathrm{mil}$ visitantes de todos os países do mundo.” (VAN OUDENAREN, [2012?], tradução nossa). A satisfação do usuário também creditou valor aos metadados, às descrições em nível de item, e à arquitetura técnica.

Atualmente $^{18}$, 193 países são representados na BDM, em 145 idiomas, com um total de 19.147 itens (correspondente a 1.057.175 arquivos), nomeadamente imagens e fotografias, jornais, livros, manuscritos, diários, mapas, registros fonográficos e filmes, fornecidos por 158 associados em 60 países: 118 bibliotecas, 19 museus, 5 arquivos, 16 outros, dentre os quais universidades e institutos.

Apesar de a BDM ter sido delineada com objetivos propostos por Billington, no website da Biblioteca Digital Mundial ([2009?]) estão indicados:

- Promover a compreensão internacional e intercultural;

- Expandir o volume e a variedade de conteúdo cultural na Internet;

- Fornecer recursos para educadores, acadêmicos e o público em geral;

- Desenvolver capacidades em instituições parceiras, a fim de reduzir a lacuna digital dentro dos e entre os países.

Por estar incluída no programa Memória do Mundo da UNESCO, a BDM tem como legado a preservação e o pleno acesso do patrimônio documental mundial: "Um dos objetivos do conteúdo da Biblioteca Digital Mundial será trabalhar em estreita colaboração com o programa Memória do Mundo, da UNESCO, visando tornar as versões digitais destes acervos acessíveis ao público.” (BIBLIOTECA DIGITAL MUNDIAL, [2009?]). 


\section{Mundaneum e Biblioteca Digital Mundial: alguma relação?}

Como apresentado no decorrer do tópico anterior, o projeto Mundaneum de Paul Otlet visava à centralização e disseminação do conhecimento. Por ansiar, de forma utópica, que o Mundaneum se configurasse como o centro de informações das nações, pode-se inferir que o projeto de Otlet era reunir toda produção intelectual do mundo. Neste contexto, tanto o Mundaneum quanto a BDM são pautadas no acesso à informação mundial, nacional e regional.

Quanto à concepção de paz mundial, presente fortemente no discurso de Otlet, mostra-se com ressalvas nas considerações de Billington (2005), uma vez que considerou que a nova proposta não teria como trazer paz por si só. Além disso, entende-se que questões atinentes ao conflito e à paz precisam ser levadas em conta no desenvolvimento científico, visto que trabalham com a informação e a definição de novos conhecimentos.

Outra similaridade que pode ser traçada refere-se à concepção do Atlas Universal da Enciclopédia Universalis Mundaneum (EUM), por Otlet, figura 2:

Figura 2 - Uma das placas no único volume completo da Enciclopédia Universalis Mundaneum

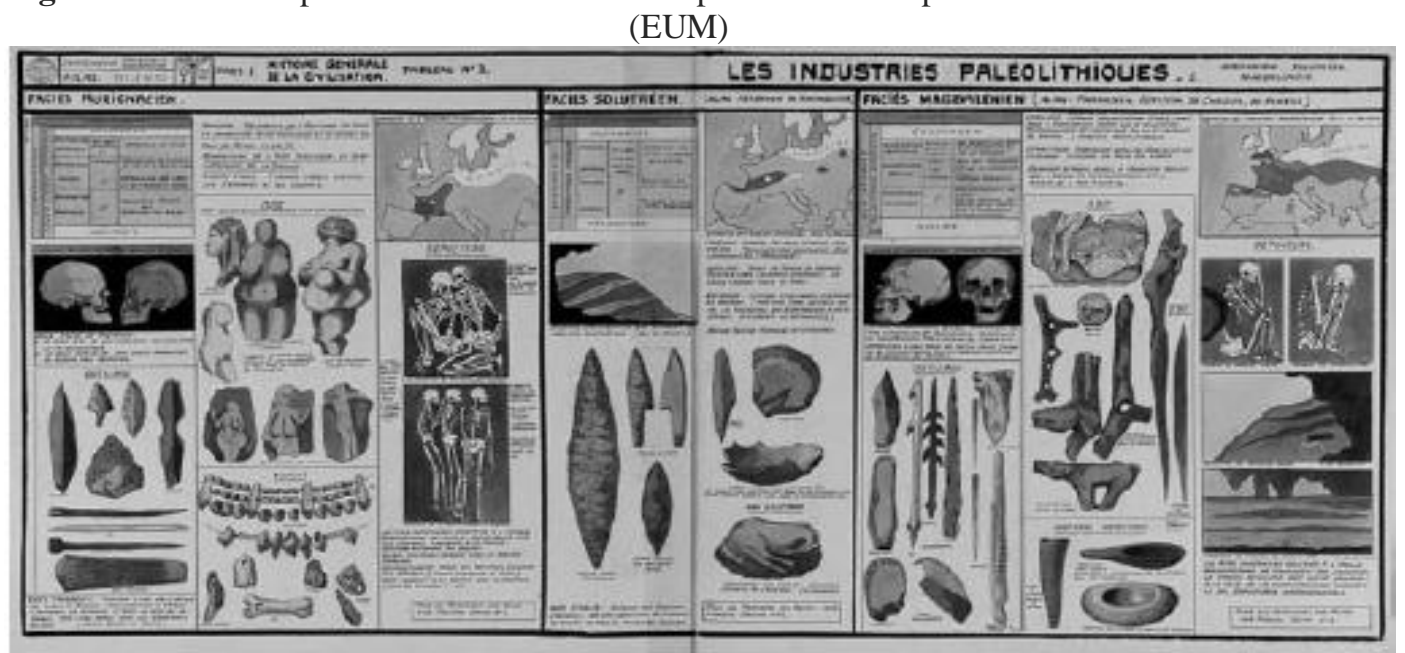

Fonte: Rayward (2010, p. 23).

A EUM era como uma enciclopédia ilustrada, um livro constituído por uma coleção de gravuras, gráficos, mapas relativos a uma ciência:

[...] o Atlas Universal foi uma enciclopédia ilustrada constituída por placas separadas. Cada placa foi dedicada à apresentação de esquemas, tabelas e ilustrações de vários tipos relacionados a um assunto específico (Otlet usou consistentemente o termo "atlas" neste sentido). Cada placa sintetizou elementos coletados de várias fontes de informação: cartões bibliográficos, livros, jornais, arquivos documentais (RAYWARD, 2010, p. 23-24). 
Compreende-se que a EUM se assemelha aos mapas interativos disponíveis na BDM, nos quais é possível escolher navegar por temas como: história dos Estados Unidos; história mundial; livros, manuscritos, gravuras e mapas chineses; iluminuras da Europa; Primeira Guerra Mundial; Rússia Imperial.

Além das semelhanças quanto aos objetivos dos dois projetos, constatam-se como comuns ao sonho-utopia de Otlet e a BDM:

a) atividades de recolhimento, seleção, organização, armazenamento e disseminação do conhecimento;

b) acesso onipresente: acesso em qualquer lugar do mundo ao mesmo tempo;

c) acesso rápido à informação: eficiência e rapidez;

d) apoio de instituições: não é composta somente de uma entidade/instituição;

e) caráter internacionalista: visando a disseminação do conhecimento por meio de informações que não se limitam a uma única nacionalidade, cooperação entre as nações;

f) variedade de recursos informacionais: manuscritos, mapas, livros raros, gravações, filmes, gravuras, fotografias, desenhos arquitetônicos e outros tipos de fontes básicas;

g) preservação da memória: disseminação, uso e preservação de dados de conteúdo cultural;

h) participação de diferentes esferas, desde a local até a internacional;

i) adoção de padrões bibliográficos e documentais;

j) definição de princípios que, embora nomeados de modo diferentes, apresentam a mesma linha conceitual;

k) disseminação do conhecimento intelectual por meios alternativos: como pela internet, televisão, rádio.

Percebe-se que o Mundaneum e a BDM têm ligações, mesmo que não declaradas nos propósitos definidos para a BDM, que trazem à tona a reflexão sobre o sonho-utopia de Otlet.

O fato de a BDM estar disponível mundialmente por conta de recursos tecnológicos associados ao acesso pela Internet, considera-se válida a visão de 
Otlet, ainda em 1935, para o acesso à informação no Mundaneum:

Todas as coisas do universo todas as coisas do homem seriam registradas remotamente quando ocorressem. Assim seria estabelecida a imagem em movimento do mundo, sua memória, seu verdadeiro duplo. Cada um, à distância, poderia ler a passagem que, ampliada e limitada ao assunto desejado, seria projetada na tela individual. Assim, todos em sua cadeira, poderiam contemplar a criação, em sua totalidade ou em algumas de suas partes (OTLET, 1935, p. 391, tradução nossa).

Todas as coisas do universo e todas as coisas do homem seriam registradas remotamente quando ocorressem. Assim seria estabelecida a imagem em movimento do mundo, sua memória, seu verdadeiro duplo. Cada um a distância poderia ler a passagem que, ampliada e limitada ao assunto desejado, seria projetada na tela individual. Assim, todos em sua cadeira poderiam contemplar a criação, em sua totalidade ou em algumas de suas partes.

Ao ser contraposta a abordagem dada por Otlet àquela apresentada por Sayão (2009, p. 13-14) para as bibliotecas digitais, infere-se semelhança ao que foi vislumbrado ainda no século passado:

A versão digitalizada dos estoques informacionais da biblioteca tradicional proporcionou a possibilidade inédita do acesso independente de distância e de tempo, o compartilhamento por mais de um usuário de uma mesma obra a um custo muito baixo e, é claro, o acesso instantâneo e fácil a uma versão digital do texto completo. [...] a emergência da web acelerou o surgimento de novos gêneros de tipos de documentos que não tinham equivalência no domínio da informação impressa e existiam somente no domínio da computação e da comunicação em rede. No contexto ciberespaço, a informação digital pode ser transportada na velocidade da luz, armazenada em densidade atômica, e convergir em novos tipos de documentos que combinam texto, imagem, gráficos, vídeo, áudio, hiperlinks, applets e tudo mais que a inovação tecnológica e força do mercado possam proporcionar.

Há que se reconhecer, porém, que a visão integrada, estrutural, interdisciplinar, correspondente às funções da vida social propostas por Otlet, com destaque para as questões biológicas, reprodutivas, econômicas, morais, intelectuais, jurídicas e políticas, não se faz notada claramente na BDM, apesar de ocorrer a participação de organismos em diferentes níveis: local, regional, nacional e internacional, o que denota um caráter diplomático.

Pontua-se também que a BDM, por estar vinculada à UNESCO e ter a coordenação por um Conselho Consultivo, fique mais sujeita às pressões 
políticas, enquanto que o Mundaneum poderia apresentar mais autonomia em sua gestão. Este apontamento não é para ser compreendido, porém, que uma ou outra forma de gestão, quer seja centralizada ou descentralizada, seja melhor ou pior, visto que, cada uma sobrevém de um momento cultural, político, social e ideológico. É fato que o papel que a BDM tem se proposto a desenvolver tem fornecido o acesso, a qualquer hora e de qualquer lugar, às coleções de conteúdo cultural de bibliotecas, arquivos e outras instituições de patrimônio cultural, de vários países.

Por conta da crença de Otlet em uma comunicação com uma linguagem flexível, por meio de novas formas de representação de ideias, a BDM pode ser comparada ao Mundaneum, visto que, com os ambientes web, conexões invisíveis, incorporadas nas redes, ligam pessoas, instituições e, porque não dizer, objetos, a uns e outros, de um e outro lado do globo, graças à internet.

\begin{abstract}
Ele acreditava que o livro no futuro não se basearia somente na linguagem que se tornou "mais flexível, mais fácil de entender, mais eficaz", mas também se basearia em "outras formas de representação de ideias que texto: ilustrações, diagramas, esquemas, uma simbologia de ideias muito melhorada" (OTLET, 1909, p. 27 apud VAN DEN HEUVEL; RAYWARD, 2011, p. 2320, destaque do autor, tradução nossa).
\end{abstract}

Considera-se Otlet, portanto, como um dos precursores da atual World Wide Web, com base, inclusive, nos conceitos de hipermídia que apresentou: “[...] novos links constantemente em minha mente, e reduzo tudo a um conceito cíclico.” (L’HOMME..., 2002). Os conceitos embutidos em termos adotados para referir-se aos ambientes digitais de acesso online podem ser notados no discurso de Otlet (2018, p. 605):

Sob nossos olhos encontra-se em processo de construção um imenso maquinário destinado ao trabalho intelectual. Ele é composto pela combinação de diferentes máquinas especiais existentes, das quais, apesar do individualismo e do particularismo dos inventores, podem ser entrevistas necessárias ligações. Esse maquinário está hoje quase que exclusivamente a serviço da indústria, do comércio e das finanças. Amanhã ele será colocado a serviço da administração e do trabalho científico e então será possível colher maravilhosos resultados.

Pode-se contextualizar o quão importante é a disponibilização de conteúdos digitais para a promoção do acesso à informação. 


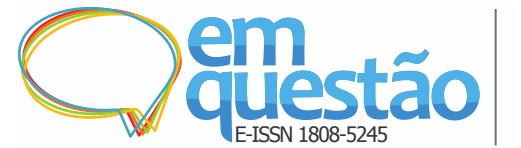

Mundaneum e Biblioteca Digital Mundial: relações

possíveis?

Zaira Regina Zafalon e Mariana Nóbrega de Sá

\section{Considerações arriscadas}

Outras relações entre as propostas de Otlet e projetos contemporâneos são possíveis de serem estabelecidas. Este estudo, entendido como Otlet revisitado, fez uma das aproximações possíveis. Acredita-se que os objetivos definidos para o presente artigo tenham sido alcançados e que os argumentos apresentados como resposta à questão proposta tenham dado conta de ensejar discussões sobre as relações entre o Mundaneum e a Biblioteca Digital Mundial.

Arrisca-se a considerar que a BDM apresente forte relação com o Mundaneum, embora essa identificação não tenha sido feita nas fontes documentais encontradas. A BDM, se posta como a realização do sonho-utopia de Otlet, reúne e dissemina o conhecimento internacional, intercultural, com recursos informacionais dos mais diversos períodos, países, formatos e áreas do conhecimento. Considera-se que identificar, selecionar, organizar, armazenar, integrar, compatibilizar linguagens e definir o usuário como foco do processo das atividades da BDM seja de fato complexo, todavia tem se mostrado um processo de grande alcance e importância.

Apesar de identificar um forte vínculo da BDM com a proposta definida para o Mundaneum, não foi notada - e, como toda pesquisa, poderão ocorrer ressalvas dos leitores quanto a essa consideração, mas, como dito, é uma avaliação arriscada - a presença da proposta de Otlet para que a BDM tivesse visão integrada, estrutural, interdisciplinar, correspondente às funções da vida social: biológica, reprodutiva, econômica, moral, intelectual, jurídica e política.

É preciso observar que, embora não tenha sido encontrado estudo da relação entre o Mundaneum e a BDM, há vários estudos que apresentam as propostas de Otlet como inovadoras em termos do que se chamou depois como navegação hipertextual, Internet e biblioteca digital, fatores presentes e consagrados na BDM.

Aposta-se na indicação de que o grande sonho de Otlet, em amplitude, realizou-se na BDM por conta de recursos tecnológicos, claramente por conta da Internet, da adoção de padrões de metadados que favorecem a conversão, a integração e a interoperabilidade entre sistemas, e do cenário político, inclusive por conta da participação da UNESCO. Cabe lembrar, inclusive, que a proposta 
da Liga das Nações também foi feita por Otlet! Quanto aos projetos políticos em causa, haveria muito a ser discutido, uma vez que a questão é complexa, principalmente no que se refere aos estudos sobre as ações de Otlet, que precisam ser mais explorados ou ainda produzidos. As ações de Otlet foram continuamente marcadas por vieses políticos de grande envergadura, fossem em sua proposição (o pacifismo e o internacionalismo), fossem em seu desenvolvimento (apoio recebido ou quase recebido para seu desenvolvimento, já que foi aventado usar as fontes advindas da exploração do Congo belga, assim como, houve um flerte com o governo de Mussolini). A própria relação entre a Liga das Nações e a UNESCO são projetos políticos que também cabe explorar.

Otlet propôs métodos e instrumentos inovadores de organização da informação, em geral pautado nos instrumentos já existentes. Ele desenvolveu a Classificação Decimal Universal (CDU), o princípio monográfico (o que permitiu priorizar a produção de registros de analíticas), a noção de análise e síntese, a adoção de uma diversidade maior de tipologias documentais etc. Desse modo, a contribuição de Otlet para a BDM está posta: a BDM não é apenas uma base de dados, mas um complexo sistema de informação.

Sem dúvida, merece destaque a participação da Biblioteca Nacional do Brasil como coparticipante da proposta, feito que elevou a cultura nacional a cenários internacionais, até mesmo porque o português não é considerado como um idioma oficial da UNESCO. A BDM viabiliza o acesso ao patrimônio cultural e possibilita que a memória do Brasil, por questão das dimensões continentais, não se restrinja somente à sua região de origem, mas que seja mais abrangente e divulgada em escala mundial.

Compreende-se que, com este estudo, novas questões sejam levantadas, correlatas ao objeto aqui estudado e que poderão ir além da pesquisa realizada. Ficou uma semente.

\section{Referências}

BIBLIOTECA DIGITAL MUNDIAL. Sobre a Biblioteca Digital Mundial: experiência. [2009?]. Disponível em: https://www.wdl.org/pt/background/. Acesso em: 30 abr. 2019.

BILlingtON, J. A view of the Digital World Library. 2005. Disponível em: 
https://2001-2009.state.gov/p/io/unesco/51671.htm. Acesso em 27 abr. 2019.

BRITANNICA ESCOLA. Liga das nações. [2019]. Disponível em: https://escola.britannica.com.br/levels/fundamental/article/Liga-dasNa\%C3\%A7\%C3\%B5es/481713. Acesso em 30 abr. 2019.

FONTOURA, M. C. A documentação de Paul Otlet: uma proposta para a organização racional da produção intelectual do homem. 2012. Dissertação (Mestrado em Ciência da Informação) - Universidade de Brasília, Brasília, 2012. Disponível em:

http://repositorio.unb.br/bitstream/10482/11909/1/2012_MarceloCarneirodaFont oura.pdf. Acesso em: 24 jun. 2019.

GANTZ, J.; REINSEL, D. The digital universe in 2020: Big data, bigger digital shadows, and biggest growth in the far east. IDC Analyze the Future, Framingham, v. 3, p. 1-16, dez. 2012. Disponível em: https://www.emc.com/collateral/analyst-reports/idc-the-digital-universe-in2020.pdf. Acesso em: 30 abr. 2019.

L'HOMME qui voulait classer le monde. Direção de Françoise Levie. Produção de Sofidoc. Belgian: RTBF Television, 2002. Vídeo. Disponível em:

http://iptv.usp.br/portal/video.action?idItem=5941. Acesso em: 30 abr. 2019.

LIBRARY OF CONGRESS. Biographies: James H. Billington (1928-2018). [2018?]. Disponível em: https://www.loc.gov/item/n80020417/james-hbillington-1929/. Acesso em: 29 abr. 2019.

LIBRARY OF CONGRESS. James H. Billington. [2000?]. Disponível em: http://www.loc.gov/bookfest/author/james_h_billington. Acesso em: 29 abr. 2019.

OTLET, P. Monde: essai d'universalisme: connaissance du monde, sentiment du monde, action organisée et plan du monde. Bruxelles: Mundaneum,1935. Disponível em: https://biblio.ugent.be/publication/378026. Acesso em: 30 abr. 2019.

OTLET, Paul. Tratado de documentação. Brasília: Briquet de Lemos, 2018. Disponível em: http://repositorio.unb.br/bitstream/10482/32627/1/LIVRO_TratadoDeDocument a\%C3\%A7\%C3\%A3o.pdf. Acesso em: 30 abr. 2019.

POZZATTI, Valéria Rodrigues de Oliveira et al. Mundaneum: o trabalho visionário de Paul Otlet e Henri La Fontaine. Revista ACB, Florianópolis, v. 19, n. 2, p. 202-209, set. 2014. ISSN 1414-0594. Disponível em:

https://revista.acbsc.org.br/racb/article/view/963. Acesso em: 24 jun. 2019.

RABELLO, R. Ações de informação no Instituto Brasileiro de Informação em Ciência e Tecnologia. Ciência da Informação, Brasília, v. 41, n. 2/3, p.104121, maio/dez. 2012. Disponível em: 
http://revista.ibict.br/ciinf/article/view/1339/1518. Acesso em: 30 abr. 2019.

RAYWARD, W. B. (adapt.). Mundaneum: archives of knowledge. Occasional Papers, [s. l.], n. 215, p. 1-46, may 2010. Disponível em:

https://www.ideals.illinois.edu/bitstream/handle/2142/15431/Rayward_215_WE B.pdf?sequence=2\&isAllowed=y. Acesso em: 30 abr. 2019.

RAYWARD, W. B. Organização do conhecimento e um novo sistema político mundial: ascensão e queda e ascensão das ideias de Paul Otlet. In: OTLET, Paul. Tratado de documentação. Brasília: Briquet de Lemos, 2018. p. xi-xxvii. Disponível em:

http://repositorio.unb.br/bitstream/10482/32627/1/LIVRO_TratadoDeDocument a\%C3\%A7\%C3\%A3o.pdf. Acesso em: 30 abr. 2019.

RIEUSSET-LEMARIÉ, I. P. Otlet's Mundaneum and the International Perspective in the History of Documentation and Information Science. Journal of the American Society for Information Science, New York, v. 48, n. 4, p. 301-309, apr. 1997. Disponível em: http://onlinelibrary.wiley.com/doi/10.1002/(SICI)10974571(199704)48:4\%3C301::AID-ASI3\%3E3.0.CO;2-\%23/epdf. Acesso em: 30 abr. 2019.

SAYÃO, L. F. Afinal, o que é a biblioteca digital? Revista USP, São Paulo, n. 80, p. 6-17, dez. 2008/fev. 2009. Disponível em: https://www.revistas.usp.br/revusp/article/view/13709/15527. Acesso em: 30 abr. 2019.

VAN DEN HEUVEL, C.; RAYWARD, W. B. Facing Interfaces: Paul Otlet's visualizations of data integration. Journal of the American Society for Information Science and Technology, New York, v. 62, n. 12, p. 2313-2326, dez. 2011. Disponível em: http://onlinelibrary.wiley.com/doi/10.1002/meet.1450430173/full. Acesso em: 30 abr. 2019.

VAN OUDENAREN, J. The World Digital Library. [2012?]. Disponível em: http://docplayer.net/44246485-The-world-digital-library.html. Acesso em 29 abr. 2019.

VOSSOUGHIAN, N. The language of the world museum: Otto Neurath, Paul Otlet, Le Corbusier. Associations transnationales, Bruxelles, v.1, n. 2, jan./jun. 2003. Disponível em: http://www.academia.edu/3127404/The_Language_of_the_World_Museum_Ott o_Neurath_Paul_Otlet_Le_Corbusier. Acesso em: 30 abr. 2019.

WIKIMEDIA COMMONS. La cité mondiale. 1 ilustração. 2016. Disponível em: https://commons.wikimedia.org/wiki/File:La_cit\%C3\%A9_mondiale.jpg. Acesso em: 30 abr. 2019. 
WRIGHT, A. Cataloging the world: Paul Otlet and the birth of the information age. New York: Oxford University Press, 2014. Ebook.

\title{
Mundaneum e World Digital Library: possible relationships?
}

\begin{abstract}
Paul Otlet's contribution to Information Science, in particular in Documentation studies, is remarkable. In the historical context between the two world wars, Otlet dreams of the Mundaneum, an information and knowledge center for world peace. Between 2005 and 2006, the Library of Congress, UNESCO and five other institutions, among them the National Library of Brazil, propose the creation of the World Digital Library. Because they believed in the importance of cultural and documentary heritage institutions in curating informational objects for historical, educational, political and social formation, answers were sought to the question: would the World Digital Library be the realization of Mundaneum? With the general objective of identifying approximations between the Mundaneum and the World Digital Library, from a historical perspective, the research covers exploratory objectives. With a qualitative and applied approach, bibliographical and documentary research is used to make the results. He risks to consider that the World Digital Library has a strong relationship with the Mundaneum, although this identification has not been made in the documentary sources found. The World Digital Library stands as the fulfillment of Otlet's dream-utopia, bringing together and disseminating international, intercultural knowledge with information resources from the most diverse periods, countries, formats and areas of knowledge. Despite the strong links between them, the presence of Otlet's proposal for the World Digital Library project to have an integrated, structural, interdisciplinary vision corresponding to the functions of social life was not noticed, as Otlet proposed: biological, reproductive, economic, moral, intellectual, legal and political.
\end{abstract}

Keywords: Mundaneum. World Digital Library. Paul Otlet. UNESCO.

Recebido: 03/05/2019

Aceito: 17/07/2019

\footnotetext{
${ }^{1}$ Apesar de o Palácio Mundial ser, na literatura, por vezes nomeado como Cidade Mundial, $L a$ Cite Mondiale, World Palace e World City, é possível identificar que Palácio Mundial referiase a um edifício, com placa de identificação à entrada, que agregava as coleções de documentos, incluindo museu, biblioteca, laboratório, universidade, e que deveria estar localizado em uma Cidade Mundial.

${ }^{2}$ As autoras reconhecem que o recorte adotado para a pesquisa bibliográfica é de bases de dados que cobrem, em sua grande maioria, a literatura norte-americana, e em inglês. É importante considerar, porém, que a literatura sobre Documentação é, em grande parte, escrita na Europa,
} 
em francês, espanhol ou alemão. Daí a ideia de continuidade da pesquisa de modo que outras bases de dados sejam consideradas.

${ }^{3}$ Apesar de, em um primeiro momento, a relação entre Otlet e Mundaneum parecer irrelevante nas buscas, visto o fato de ele ser o principal mentor do Mundaneum, essa opção foi feita por se buscar aumentar o número de documentos recuperados nos resultados.

${ }^{4}$ Optou-se por esta forma de apresentação dos dados tendo em vista o respeito ao limite de páginas proposto pela revista.

5 Títulos de periódicos com até duas ocorrências não foram apontados no artigo.

${ }^{6}$ Autores com até duas publicações não foram apontados no artigo.

${ }^{7}$ A informação de sete milhões tem como fonte o documentário de Otlet, que remete ao acervo de 1905 (L'HOMME ..., 2002). Entretanto, Fontoura (2012) e Pozzatti et al. (2014) indicam entre 12 e 15 milhões.

${ }^{8}$ Em Otlet (2018, p. 270) há a indicação de que o documento em que consta a redação da Liga das Nações é: "Paul Otlet. Constitution mondiale de la Société des Nations. Paris, Cres, 1917." Não foi possível, porém, ter acesso a esse documento. Segundo consta em Britannica Escola [(2019)]: “A Liga das Nações (ou Sociedade das Nações) foi uma entidade idealizada pelos países que venceram a Primeira Guerra Mundial (1914-18). Eles queriam que a liga servisse como um lugar em que os países pudessem resolver as disputas por meio de negociações, em vez de combates. [...] O fracasso da Liga das Nações em evitar a guerra revelou como ela tinha se enfraquecido. A entidade não convocou nenhuma reunião durante o conflito. Após a guerra, em 1946, foi substituída por uma nova entidade, a Organização das Nações Unidas (ONU)."

9 "Querido Jean, querido filho, todas as minhas lembranças de você como um pequeno menino me inundaram de novo, tão boas como a memória de um jovem. Nele, vejo tudo da juventude dizimada, todo o sangue que fluiu, os milhões que outras balas, em outros campos de batalha foram atingir. E eu sinto em mim algo mais forte que o ódio, não contra o homem, mas contra todo o abominável sistema que provocou este cataclismo. Estou mais empenhado do que nunca numa vingança. Eu vou vingá-lo trabalhando, para que seu sacrifício signifique algo e sirva como progresso para o mundo, finalmente livre de guerras." (L'HOMME..., 2002).

${ }^{10}$ Esta pesquisa se propõe a estudar a BDM e o Mundaneum a partir desta perspectiva. Apesar de certa aproximação entre o RBU e a BDM, a diferença está, de modo simplificado, no fato de a BDM ter textos completos anexos aos registros dos mesmos. Entretanto, conceitualmente, a RBU seria a espinha dorsal do Mundaneum; o Mundaneum se notabiliza em ir além do RBU.

${ }^{11}$ Otlet, Paul. Monde. Bruxelles: Editiones Mundaneum; Van Keerberghen \& Fils, 1935. p. 124.

${ }^{12}$ Para conhecer a apresentação destes conceitos por Otlet, veja, também, Otlet (2018, p. 650$651)$.

${ }^{13}$ Otlet (2018, p. 652-653).

${ }^{14}$ A distância entre um parque e outro é de cerca de $700 \mathrm{~m}$.

${ }^{15}$ Van Oudenaren ([2012?]) aponta que a dificuldade também viria por conta do cenário mundial quanto ao desenvolvimento da tecnologia e à sua apropriação pelas pessoas à época do início dos trabalhos em prol da BDM: 13 anos depois de lançada a Internet; sete anos do início do acordo entre Estados Unidos e Rússia para colaboração em bibliotecas digitais; fase de lançamento de aplicativos e dispositivos móveis para acesso a conteúdo online (Google Books, em 2006, iPhone e Kindle, em 2007); e a revolução de buscas na web com o Google.

${ }^{16} \mathrm{O}$ projeto Memory of the World, da UNESCO, pode ser conhecido ao acessar o website https://en.unesco.org/programme/mow.

${ }^{17}$ Estudos referentes aos metadados que estão elencados aqui fazem parte de outra pesquisa sob orientação de Zaira Regina Zafalon.

${ }^{18}$ Dados coletados em 27 de abril de 2019 no site institucional da Biblioteca Digital Mundial. 